\title{
Debunking arguments and metaphysical laws
}

\author{
Jonathan Barker ${ }^{1}$ (1)
}

(C) Springer Nature B.V. 2019

\begin{abstract}
I argue that one's views about which "metaphysical laws" obtain-including laws about what is identical with what, about what is reducible to what, and about what grounds what - can be used to deflect or neutralize the threat posed by a debunking explanation. I use a well-known debunking argument in the metaphysics of material objects as a case study. Then, after defending the proposed strategy from the charge of question-begging, I close by showing how the proposed strategy can be used by certain moral realists to resist the evolutionary debunking arguments.
\end{abstract}

Keywords Debunking arguments - Defeaters · Material objects · Laws of metaphysics · Identity · Reduction · Grounding

Moral beliefs, mathematical beliefs, religious beliefs, and beliefs about which composite objects exist have all been the target of so-called "debunking" arguments. Debunking arguments typically begin with the claim that there is a debunking explanation of some type of belief we hold. A debunking explanation is a complete causal explanation of the origins of some type of belief, which makes no reference to the facts that are those beliefs' putative subject matter. Once we concede the existence of such an explanation, the debunker contends, we thereby lose our justification for holding those beliefs.

In this paper I shall argue that one's views about which "metaphysical laws" obtain - such as the laws about what is identical with what, about what is reducible to what, and about what grounds what—can be used block the epistemic threat posed by debunking arguments.

Jonathan Barker

Jrb5jx@virginia.edu

1 University of Notre Dame, Notre Dame, USA 
I will develop the proposed strategy by using a well-known debunking argument in the metaphysics of material objects as a case study. Then, after defending the proposed strategy from the charge of question-begging, I shall argue that certain moral realists can use the proposed strategy to reply to the evolutionary debunking arguments in meta-ethics. I will conclude by outlining the strategy in its most generalized form.

\section{The overdetermination argument}

Outside the metaphysics seminar room, our beliefs about the existence of such ordinary composite objects such as baseballs, mountains, trees, and animals-our "object beliefs" - are based primarily on our apparent perceptual experiences as of those objects. ${ }^{1}$ It is plausible that these perceptual experiences as of composite objects-or "object experiences," for short-give us prima facie justification for believing that objects of the relevant sort exist. ${ }^{2}$ For example, your having a perceptual experience as of a baseball prima facie justifies you in believing that there is a baseball.

We can, of course, lose our perceptual justification for our object beliefs. Specifically, we can gain "defeaters" for our object beliefs. ${ }^{3}$ Let us say that a belief of yours D is a defeater for some other belief of yours B just in case holding D makes it rationally impermissible for you to continue holding $\mathrm{B}{ }^{4}$ The perceptual debunker concedes our object beliefs enjoy prima facie justification and that, prior to encountering a debunking argument, it is perfectly rational of us to hold the object beliefs we do. However, the perceptual debunker's goal is to give us a defeater for those object beliefs. ${ }^{5}$

As a case study, consider Trenton Merricks' well-known perceptual debunking argument, the Overdetermination Argument (the OA). The argument has two steps.

\footnotetext{
${ }^{1}$ Korman (2015) and Merricks $(2001,2016)$ all emphasize the primacy of our causal-perceptual reasons for believing in ordinary composite objects.

${ }^{2}$ Note that my use of the phrase "object experience" does not commit me to the controversial view that our perceptual experiences literally have high-level kind-membership properties as constituents. For example, when I say that we sometimes have baseball experiences, I am not thereby committing myself to the view that the property of being a baseball is a literal constituent in those experiences. For all I say in this paper, perhaps baseball experiences have only simple, lower-level properties-such as the property of being round, the property of being white with red stitching, the property of being such-and-such a size, etc.-as its constituents. Korman (2015) contains a helpful discussion of how this difficult issue in the philosophy of perception relates to our perceptual evidence for composite material objects.

${ }^{3}$ Merricks (2003) and Korman (2015) Chapter 7 both understand debunking arguments targeting our object beliefs as attempts to give us epistemic defeaters. Moon (2017) and Korman forthcoming understand debunking arguments more generally as attempts to give us defeaters for the beliefs they are targeting.

${ }^{4}$ Plantinga (1993), p. 361.

5 Specifically, the debunker claims that we gain an "undercutting" defeater for our object beliefs. A belief that $\mathrm{p}$ is an undercutting defeater for a belief $\mathrm{q}$ just in case the belief that $\mathrm{p}$ is a defeater for the belief that q, but your believing that $\mathrm{p}$ does not also justify you in believing that $\mathrm{q}$ is false. See Plantinga (2011), p. 41.
} 
In the first step, Merricks argues that there is a complete causal explanation of our object experiences-and thus our object beliefs-that does not include the composite objects themselves. Specifically, he argues that-whether or not composite objects exist-the causal activities of microphysical particles arranged in certain object-shaped ways fully causally explain why we have the object beliefs we do. ${ }^{6}$

The first step of the OA begins by asking us to suppose that there are composite objects. For example, suppose there are baseballs. Now suppose that a baseball strikes a glass window, causing it to shatter. Surely there is also a complete causal explanation of the window's shattering that only involves the joint activities of atoms arranged baseball wise. More generally, if there are baseballs, then any effect caused by a baseball is also fully causally explained by the activities of the baseball's composing parts, the atoms arranged baseball wise.

Now suppose some atoms arranged baseball wise-the bs-compose a baseball. And suppose that baseball causes you, via causing you to have a baseball experience, to form the belief that there is a baseball. Since everything the baseball causes is also fully caused by its composing parts, the bs, it follows that your belief that there is a baseball-your "baseball belief" - is fully causally explained by the joint activities of the bs.

On the other hand, suppose the bs do not compose a baseball. Then your visual experiences as of a baseball —and thus your baseball belief-is not caused by a baseball. Instead, your belief that there is a baseball is solely caused by the joint activities of the bs. Therefore, if the bs do not compose a baseball, then your baseball belief is fully causally explained by the joint activities of the bs.

We can thus formulate the first step of Merricks' OA as follows ${ }^{7}$ :

(OA1) If there is a baseball, then my baseball belief is fully caused by the bs.

(OA2) If there is no baseball, then my baseball belief is fully caused by the bs.

(OA3) Either there is a baseball or there is no baseball.

(OA4) Therefore, my baseball belief is fully caused by the bs (from OA1, OA2, and OA3).

Establishing the truth of OA4 is the first step of Merricks' Overdetermination Argument (OA). In the second step, Merricks argues that OA4 is a debunking explanation of your belief that there is a baseball. In other words, the second step is

\footnotetext{
${ }^{6}$ Strictly speaking, Merricks only argues that our beliefs about which inanimate composite objects exist are fully causally explained by the joint work of microphysical particles appropriately arranged. For, according to Merricks, our beliefs in the existence of human organisms are not ultimately based on causal-perceptual experiences and therefore escape debunking. See Merricks (2001), pp. 85-117.

7 Notice that this version of the Overdetermination Argument does not use the word "overdetermination." Formulations of the argument using that term are susceptible to objections based on what is and is not genuine overdetermination. See Thomasson (2007), Sider (2003) and Schaffer (2010a) for versions of this objection. However, as Merricks points out in Merricks (2016) fn. 1, such debates about the nature of overdetermination are not ultimately relevant to the success of the debunking version of the Overdetermination Argument. Korman (2015) Chapter 10 is one of the few discussions of Merricks's Overdetermination Argument to recognize this point.
} 
the claim that your acceptance of OA4 gives you a defeater for your otherwise justified baseball belief.

In the second step of the OA, Merricks argues that anyone who realizes the truth of OA4 thereby loses whatever justification she had for her baseball belief. He offers the following analogy:

You gaze upon the Emerald City. Its buildings appear to be green. You are then informed that your glasses have green lenses. Thus you learn that the buildings would appear green to you even if they were some other color. And so you are no longer justified in believing that the buildings are green. Let us say that your belief about your glasses defeats any justification, based only on your "green building" sensory experiences, for your belief that the buildings are green. ${ }^{8}$

Call this the "Emerald City case." Notice that we can distinguish two defeaters in the Emerald City case. ${ }^{9}$ First, you realize that the city would appear green even if it were not green. And so, presumably, you realize that you would have believed that the city is green even if it were not green. You have thus realized that your "green city belief" is insensitive to the facts about whether the city is green. This realization is a defeater for your green city belief.

But you have also realized something about the causal origins of your green city belief-you have realized that the color of your visual experiences as of a city are fully causally explained by the green tint on your glasses. And so, you can infer, your belief that the city is green in color is fully causally explained by the green tint of your glasses. This realization about the causal origins of your green city belief, all on its own, is a defeater for that belief.

You thus have two defeaters in the Emerald City case-your realization about the causal origins of your green city belief, and your realization that your green city belief is insensitive to the facts about whether the city is green. ${ }^{10}$

Now consider a second case:

You gaze upon a grassy field. It visually appears to you as if there is a baseball, sitting in the grass. You then realize that your visual experience as of a baseball is caused by a bunch of things, the atoms arranged baseball wise, acting in concert. So you also realize that, even if there were no baseball, you would still have had a visual experience as of a baseball.

Call this simply "the Baseball case." According to Merricks, your epistemic situation in the Emerald City case is relevantly analogous to your situation in the Baseball case. As in the Emerald City case, it seems that you have two defeaters for your baseball belief.

\footnotetext{
8 Merricks (2003), pp. 22-23.

9 Korman and Locke forthcoming and Korman forthcoming are two of the only discussions that explicitly distinguish between these two defeaters.

${ }^{10}$ Korman and Locke persuasively argue that the realized "explanatory disconnect" defeater is more fundamental than the realized insensitivity defeater. If this paper's central thesis is correct, however, both of these putative defeaters can be deflected.
} 
First, the mere realization that your baseball visual experience-and thus your baseball belief - is fully causally explained by the joint work of the atoms arranged baseball wise, all by itself, is a defeater for your baseball belief. Your second defeater is the realization that you still would have had a visual experience as of a baseball—and thus you still would have held your baseball belief-even if there were no baseball.

Clearly, your epistemic situation in the Baseball case just is the epistemic situation you are in upon conceding the truth of OA4 of Merricks' OA. Therefore, conceding the truth of OA4 gives you two defeaters for your baseball belief. Of course, Merricks thinks you have analogous defeaters for your other object beliefs as well. Once you see how the OA generalizes, you will have defeaters for your belief in the existence of tables, chairs, trees, mountains, and every other putative composite object.

I shall argue that whether or not you have any defeaters in the Baseball case depends upon what background beliefs you have. For, so I shall argue, certain of your background beliefs can be used as "defeater-deflectors." Section 2 introduces and explains the notion of a defeater-deflector. Sections 3-6 argue that certain beliefs about which metaphysical laws obtain can serve as legitimate, non-circular defeater-deflectors. Section 7 applies the strategy to evolutionary debunking arguments metaethics.

\section{Defeater-deflectors}

Whether or not some belief $\mathrm{D}$ is a defeater for you does not depend on the propositional content of that belief alone. In addition, a belief D is a defeater for you only if you have no other belief or beliefs that are "defeater-deflectors." 11 Roughly, defeater-deflectors are justified beliefs that prevent some prima facie justified belief B from being defeated by a potential defeater D. ${ }^{12}$

Alvin Plantinga gives the following example of a defeater-deflector:

You [get] a defeater for your belief that you see a sheep in the field if I, whom you know to be the owner of the field, come along and tell you that although there is no sheep in the field, there is a canine sheep look-alike that often frequents the field. But you won't get a defeater, here, if you already think that I am unreliable on this topic, or that I have a lot to gain by getting you to doubt that there is a sheep there.... In these cases the looming defeater (defeater

\footnotetext{
${ }^{11}$ Not to be confused with a "defeater-defeater". A belief E is a defeater-defeater just in case at some time $\mathrm{t} \mathrm{I}$ hold belief $\mathrm{D}$ and $\mathrm{D}$ is a defeater for $\mathrm{B}$ at $\mathrm{t}$, and then at some later time $\mathrm{t}+1 \mathrm{I}$ hold $\mathrm{E}$ and $\mathrm{E}$ is a defeater for D. See Plantinga (2011), pp. 259-64 for more on defeater-deflectors and Moon forthcoming for a discussion of the role of defeater-deflectors versus defeater-defeaters in the moral debunking literature.

12 I shall assume here and throughout the paper that a belief of yours can serve as a defeater-deflector only if you are justified in holding that belief. That is, no irrationally held or unjustified belief can serve as a legitimate defeater-deflector. The justificatory status of defeater-deflectors will re-arise in Sect. 7.
} 
belief) will be deflected. ${ }^{13}$

So your belief that I am unreliable on the topic of sheep and dog-sheep lookalikes is a defeater-deflector.

Moreover, your belief that I am unreliable on the topic deflects the looming defeater in the following way: that belief renders it irrational for you to even form the belief that dog-sheep lookalikes regularly pass through this field or, at least, renders it irrational for you to form that belief on the basis of my testimony alone. If I had formed the belief that dog-sheep lookalikes regularly pass through the field, then that belief would have been a defeater for my belief that there is a sheep in the field.

So at least some defeater-deflectors work by preventing you from gaining some belief D such that, if you were to hold D, D would be a defeater. However, there is a second way that a belief can deflect an incoming defeater. Consider the following variation of the dog-sheep case:

One day, you have a visual experience as of a sheep in the field. You form the belief that there is a sheep in the field. I, whom you know to be the trustworthy owner of this field, then mention to you that dog-sheep lookalikes frequent this particular field. You believe what I tell you. However, you also recently received some interesting information from a very reliable source: in this geographical area, sheep and dog-sheep lookalikes always travel in pairs. The canine follows the sheep to open, grassy pastures. There, the canine hunts for small rodents in the tall grass, while the sheep grazes peacefully in the open field without fear of predators. No dog-sheep lookalike is ever more than a few yards from its sheep friend, and no sheep is ever more than a few yards from its dog-sheep lookalike friend. As a result, you conclude that I have given you no reason at all to give up your belief that there is a sheep in the field.

In this version of the case-unlike in Plantinga's original version-you do come to hold the belief that dog-sheep lookalikes frequent this field. However, in this case, that new belief does not defeat your belief that there is a sheep in the field. For you have another belief - the belief that if there is a dog-sheep lookalike in the field then there is a sheep in the field and vice versa-that prevents your realization about dog-sheep lookalikes frequenting this field from having any defeating force.

We can now distinguish between two kinds of defeater-deflectors: "neutralizing" deflectors, on the one hand, and "shielding" deflectors, on the other. Neutralizing deflectors prevent some newly held belief from being a defeater. Shielding deflectors, on the other hand, prevent you from coming to hold the potential defeating belief at all.

A single belief can simultaneously serve as a neutralizing deflector and as a shielding deflector. For example, your belief that sheep and dog-sheep lookalikes always travel in pairs serves as both a neutralizing deflector and a shielding deflector.

13 Plantinga (2011), p. 260. 
First, that belief neutralizes the potential defeating force of your newly held belief that dog-sheep lookalikes frequent this field. Second, that belief shields you from coming to believe that your belief that there is a sheep in the field is insensitive. Since sheep are always accompanied by sheep-dog lookalikes and vice versa, you reason, if there were no sheep in the field then neither would there have been a dog-sheep lookalike in the field. And if there had neither been a sheep nor a dog-sheep lookalike, you would not have believed that there is a sheep in the field. Therefore, if there had been no sheep in the field then you would not have believed that there is a sheep in the field.

\section{Identity}

Consider the following case:

You have a visual experience as of a green city. You form the belief that the city is green. Incidentally, you also happen to know that 'verde' is Spanish for 'green.' And you have concluded from this that, for anything $\mathrm{x}$, if $\mathrm{x}$ is green then $x$ 's being green is identical with x's being verde. You then realize that your green city experience-and thus your belief that the city is green-is fully causally explained by the fact that the city is verde.

Call this the "Color Identity" case. It should be clear that your realization about the origins of your green city experience does not give you any defeaters for your green city belief. For your background belief, that if something is green then its being green is identical with its being verde, is a defeater-deflector.

First, your verde-green identity belief is a neutralizing deflector. You have realized that your green city belief is fully causally explained by the city's being verde. However, you also believe that, if the city is green, then its being green is identical with its being verde. As a result, realizing that your green city belief is causally explained by the city's being verde is akin to realizing that your green city belief is causally explained by the city's being green. Since the latter belief has no defeating force, neither does the former.

Second, your verde-green identity belief is a shielding deflector. In particular, your verde-green identity belief prevents you from concluding that your green city belief is insensitive to the facts about whether the city is green. Your verdegreen identity belief allows you to conclude that, necessarily, if the city had not been green then it would not have been verde either. Moreover, if the city had not been verde then you would not have believed that it is green. Therefore, you can conclude, if the city had not been green you would not have believed it was green.

Thus your identity belief serves to neutralize one potential threat of defeat and shields you from another. More generally, given your verde-green identity belief, it is hard to see how you could receive any defeaters merely as a result of realizing that your green city belief is caused by the city's being verde. 
Composition as Identity (or CAI) is the view that, for any xs, if the xs compose an object $\mathrm{O}$, then $\mathrm{O}$ is numerically identical with the xs. ${ }^{14} \mathrm{CAI}$ states a general "law of metaphysics" - a general fact about how entities of one kind metaphysically relate to entities of another kind (see Sect. 7). Specifically, CAI says that composite objects bear the relation of numerical identity to their composing parts.

Notice that CAI does not imply anything about the conditions under which composition occurs. So CAI does not, for example, imply that composition is unrestricted. Neither does CAI imply, for example, that any microphysical particles arranged baseball wise compose a baseball. For all CAI says, perhaps there are particles arranged baseball wise but no baseballs. ${ }^{15}$

CAI does, however, have at least one important implication about what baseballs would be like, if they existed-if there are baseballs, then they are identical with things arranged baseball wise. ${ }^{16}$ Thus, given CAI, for any particles arranged baseball wise, if those particles compose a baseball, then that baseball is identical with those particles.

Now consider the following case:

You gaze upon a grassy field. It visually appears to you as if there is a baseball, sitting in the grass. So you form the belief that there is a baseball. This belief is prima facie justified for you. You also happen to accept CAIyou believe that, for any xs, if the xs compose an $\mathrm{O}$ then $\mathrm{O}$ is numerically identical with the xs. However, you then realize that your visual experience as of a baseball is caused by a bunch of things, the bs, acting in concert.

Call this "the Baseball Identity" case. The original Baseball Case in Section I is just like the Baseball Identity Case, except that you endorse CAI in the latter case but not in the former. I shall argue that you gain no defeaters in the Baseball Identity case.

\footnotetext{
${ }^{14} \mathrm{I}$ am focusing on "strong" CAI, on which putative composites are literally identical with their composing parts, rather than so-called "weak" CAI, on which putative composites only bear some composition-like relation to their composing parts. See Lewis (1991) for a defense of weak CAI and Baxter (1988) for a defense of strong CAI.

${ }^{15}$ Perhaps you think —as I do - that it would be objectionably arbitrary for an advocate of CAI to believe in atoms arranged baseballwise but no baseballs. As Ross Cameron has argued, however, the truth of CAI does not strictly entail unrestricted composition. This lack of entailment is all I am assuming here. See Merricks (2005), Sider (2007) and Cameron (2012) for more on whether CAI entails unrestricted composition.

${ }^{16}$ Suppose that, following Markosian (1998), Parsons (2004) and McDaniel (2009), there could have been qualitatively heterogeneous extended simples. Specifically, suppose that, possibly, some baseballs are extended simples. Then it is false that the truth of CAI, all by itself, implies that baseballs are such that, if they exist, they are identical with things arranged baseballwise. Instead, CAI only implies that, if there are baseballs, then they are either identical with things arranged baseballwise $o r$ they are identical with simple baseballs. Nevertheless, given the possibility of simple baseballs, CAI at least implies the following: if there are composite baseballs, then composite baseballs are identical with things arranged baseballwise. And, in the present context, the truth of that latter claim is all I need. For I am simply offering a rely to Merricks' attempt to debunk our initially justified beliefs about the existence of composite material objects, such as composite baseballs. Fans of CAI who also countenance the possibility of simple baseballs are thus invited to read my claims about what baseballs would be like, if they existed, as implicitly restricted to composite baseballs. Thanks to an anonymous referee for raising the issue of extended simples.
} 
First, your realization that your visual experience as of a baseball is caused by the bs does not, all by itself, serve as a defeater for your baseball belief. For your acceptance of CAI serves as a neutralizing deflector-it neutralizes the threat of defeat posed by your acceptance of that causal explanation.

For, if you accept CAI, then you should think that the baseball, if it exists, is numerically identical with the bs. As a result, for you, realizing that the bs fully causally explain something is akin to realizing that the baseball itself fully causally explains something. So, for you, realizing that the bs fully causally explain why you believe there is a baseball is akin to realizing that the baseball fully causally explains why you believe there is a baseball. The latter belief surely does not defeat your baseball belief. Thus, neither does the former belief.

Note that, in using CAI as a neutralizing deflector, you have not engaged in the following form of reasoning. You have not started with the premise that the bs exist, added the additional premise that CAI is true, and then concluded that the baseball exists. To engage in that form of reasoning would be to give a philosophical argument - an arguably invalid argument—for the existence of the baseball.

Such a CAI-based argument would, if it succeeded, providing you with a new non-perceptual reason for believing that there is a baseball. What you are doing with your belief in CAI, by contrast, is much more modest. You are merely using your belief in CAI to deflect a potential defeater for your perceptually justified belief in the existence of the baseball.

Second, your acceptance of CAI acts as a shielding deflector, which prevents you from coming to think that your baseball belief is insensitive to the facts about whether the baseball exists. To begin to see this, note that the relation of numerical identity obeys the following principle of necessitation: necessarily, for any thing $\mathrm{x}$, and for any thing $\mathrm{y}$, if $\mathrm{x}$ is identical with $\mathrm{y}$ then, necessarily, if $\mathrm{y}$ exists and is located at $\mathrm{L}$ then $\mathrm{x}$ exists and is located at L. In other words, a thing's existence and spatial location supervenes, with necessity, upon the existence of that with which it is identical. ${ }^{17}$

You accept CAI. So you believe that, if there is a baseball, the baseball is numerically identical with the bs. So you can now infer that the following is true of the baseball and the bs: if there is a baseball then, necessarily, if the bs exist and are located in the field then the baseball exists and is located in the field. ${ }^{18}$

\footnotetext{
${ }^{17}$ Here is the plurally quantified analogue of this necessitation principle: for any things, the xs, and any things, the ys, if the xs are identical with the ys then, necessarily, if the ys exist and are collectively located at $\mathrm{L}$ then the xs exist and are collectively located at $\mathrm{L}$.

18 Note that CAI plus this necessitation principle implies that, if the bs compose the baseball, the mere existence of the bs-no matter how they are arranged-suffices for the existence of the baseball. Restricted composition is the thesis that some things compose a further object, while others do not. Most defenders of restricted composition will deny that, if the bs compose the baseball, then the mere existence of the bs suffices for the existence of the baseball. Instead, they will claim, only the existence of the bs together with the bs' being arranged or structured baseballwise suffices for the existence of the baseball. Thus-short of adopting contingent identity, four-dimensionalism, counterpart theory, or some other controversial metaphysical thesis-defenders of restricted composition cannot make use of the CAI-based deflection strategy. Fortunately, however, the two deflection strategies I outline in Sections IV and V respectively do not have any such untoward modal implications. For an argument that CAI implies mereological essentialism, see Merricks (1999). And for helpful discussion of CAI's modal implications,
} 
You can also infer that the following counterfactual conditional is true: if there had been no baseball in the field, then the bs either would not have existed or would not have been located in the field. ${ }^{19}$ Moreover, if the bs had either not existed at all or had not been located in the field, then there would have been nothing in the field to cause you to believe that there is a baseball. Therefore, if there had been no baseball in the field, you would not have believed that there is a baseball in the field. $^{20}$

Thus, if you accept CAI, you can conclude that your baseball belief is indeed sensitive to the baseball facts. ${ }^{21}$ As a result, your belief in CAI serves as a shielding deflector-once you have used CAI to make the relevant inferences, you ought not believe the debunker's claim that your baseball beliefs are insensitive to the baseball facts. $^{22}$

We have seen that your acceptance of CAI is both a neutralizing deflector and a shielding deflector-it simultaneously removes the defeating threat posed by your

Footnote 18 continued

see Cameron (2012) and Cameron (2014). I am grateful to Kris McDaniel and an anonymous referee for pressing me on this issue.

19 Mereological essentialism is the view that, necessarily, if object $\mathrm{O}$ exists and is composed of the xs then, necessarily, if $\mathrm{O}$ exists then the xs exist and $\mathrm{O}$ is composed of the xs. Note that counterfactual conditionals of the form "if the xs had not been here then object O would not have been here," do not imply mereological essentialism. For the truth of that counterfactual is consistent with there being possible worlds in which $\mathrm{O}$ exists and the xs do not. In order for that counterfactual to be true, all that is required is that those worlds are sufficiently distant from the actual world. Thanks to an anonymous referee for discussion.

20 Suppose that the baseball, if it exists, is identical with the bs. And consider the following claim: the bs exist but the baseball does not. That claim is not just false, it is necessarily false. For the identity facts hold of necessity. As a result, any counterfactual with that claim as its antecedent is a counterpossible. For example, "if the bs had existed and the baseball not existed then I still would have believed that there is a baseball" is a counterpossible conditional. Call that claim The Counterpossible. On the traditional LewisStalnaker semantics, counterpossibles are all trivially true. So, on the traditional semantics, The Counterpossible is trivially true. I deny, however, that conceding the truth of The Counterpossible constitutes a defeater for my belief that there is a baseball. To see this, suppose I am justified in believing that Nick exists. Suppose I am also justified in believing that Mr. Beans is identical with Nick. Given the traditional Lewis-Stalnaker semantics, I can infer that the following counterpossible is true: if Mr. Beans had existed and Nick had not existed, I still would have believed that Nick exists. Call this The Mr. Beans Counterpossible. I accept that counterpossible. But accepting The Mr. Beans Counterpossible, so I say, gives me no defeater for my belief that Nick exists. So, by the same token, conceding the truth of The Counterpossible gives me no defeater for my belief that there is a baseball. Although, for a compelling case against the traditional Lewis-Stalnaker approach to counterpossibles, see Tan forthcoming.

21 Korman forthcoming points out that defenders of composite objects might be tempted to employ this form of reasoning to deflect away the insensitivity defeater. Ultimately, however, Korman argues that once the defender of composite objects has conceded that there is a complete causal explanation of her object experiences, she is no longer entitled to this necessitation principle. I argue in Section VI below that defenders of composite objects are entitled to CAI. If I am right, defenders of composite objects who accept CAI are indeed entitled to the relevant necessitation principle and can therefore legitimately deflect the insensitivity defeater.

22 I am assuming that your belief in the truth of CAI is itself justified. After all, as I noted in footnote 12 above, only justified beliefs can serve as defeater-deflectors. See Sect. 6 for discussion of how beliefs like CAI are justified. 
realization about the causal source of your baseball belief, and it shields you from acquiring the belief that your baseball belief is insensitive to the baseball facts.

It should also be clear that, if you accept CAI, your situation in the Baseball Identity case is more analogous to your situation in the Color Identity case and less analogous to your situation in Merricks' original Emerald City case. In the Color Identity case you do not, presumably, harbor any strange beliefs about the identity of facts about the tint of your glasses with facts about the color of the city. In both the Color Identity case and the Baseball Identity case, however, you do hold identity beliefs that are capable of deflecting the incoming defeaters.

\section{Reduction}

Consider the following case:

You have a visual experience as of a green city. You form the belief that the city is green. Incidentally, you also believe that, in general, if something $\mathrm{x}$ has a determinable property $\mathrm{D}$ then $\mathrm{x}$ 's being $\mathrm{D}$ is reducible to its having some determinate of $\mathrm{D}$. In other words, you believe that if some $\mathrm{x}$ is $\mathrm{D}$ then what it is for $\mathrm{x}$ to be $\mathrm{D}$ is for $\mathrm{x}$ to have some determinate of $\mathrm{D}$. You also believe the following instance of that general principle: for any $\mathrm{x}$, if $\mathrm{x}$ is green in color, then what it is for $\mathrm{x}$ to be green is for it to be some specific shade of green. However, you then realize that green city experiences-and thus your belief that the city is green-is fully causally explained by the fact that the city is emerald in color.

Call this the "Color Reduction" case. It should be clear that your realization about the origins of your green city experience does not give you any defeaters for your green city belief. For your background "reduction" belief, the belief that if something $\mathrm{x}$ is green in color then what it is for $\mathrm{x}$ to be green is for it to be some specific shade of green, serves as a defeater-deflector.

First, your reduction belief is a neutralizing deflector. You have realized that your green city belief is fully causally explained by the city's being emerald. However, your reduction belief allows you to conclude that, if the city is green, then what it is for the city to be green is for it to be some specific shade of green. As a result, if the city is green, what it is for the fact that it is green to cause you to believe it is green just is for the fact that it is some specific shade of green to cause you to believe it is green. Thus, if the city is green, for you to realize that the city's being emerald causes your green city belief is just for you to realize that your green city belief is caused by the very fact constitutive of what it is for the city to be green.

Second, your reduction belief is a shielding deflector, preventing you from conceding that your green city belief is insensitive. For reducible facts are necessitated by those facts to which they are reduced. So you should think that if the city had not been green then it would not have been emerald. Moreover, if the city had not been emerald then you would not have believed it was green. Thus, you can conclude, if the city had not been green you would not have believed it was green. 
Thus your reduction belief serves to neutralize one potential threat of defeat and shields you from forming a belief that would be a defeater if you had formed it. More generally, given your emerald-green reduction belief, it is hard to see how you could receive any defeaters merely as a result of realizing that your green city belief is caused by the city's being emerald.

Whole-Part Reductionism (WPR) is the thesis that, for any xs, if the xs compose an object $\mathrm{O}$, then the fact that $\mathrm{O}$ exists is reduced to facts exclusively about the existence and arrangement of the xs. Equivalently, for any xs, if the xs compose object $\mathrm{O}$, then what it is for $\mathrm{O}$ to exist just is for the xs to exist and be suitably arranged. $^{23}$

Three points of clarification about WPR.

First, as formulated above, WPR implies that the reduction relation at least sometimes takes facts, such as the fact that object $\mathrm{O}$ exists, as its relata. This implication is somewhat controversial. After all, perhaps there are no such things as facts. Or perhaps, even if there are facts, the reduction relation takes only objects, rather than facts, as its relata. Fortunately, WPR has a fact-free analogue, which I formulate in a footnote. ${ }^{24}$ Those who deny that facts can be the relata of reduction are invited to make use of the fact-free analogue of the WPR.

Second, note that WPR takes no stand on the nature of the reduction relation itself. Perhaps fact $x$ 's being reduced to fact $y$ is a matter of $x$ 's having a "real definition" in terms of $y .{ }^{25}$ Or perhaps x's being reduced to $y$ is a matter of y's being a constituent in $x$ 's essence. ${ }^{26}$ Or perhaps both the reduction relation and its relata are linguistic or propositional entities. For example, perhaps for $\mathrm{x}$ to be reduced to $\mathrm{y}$ is for statements of the form ' $\mathrm{x}$ exists' to analytically or conceptually entail statements of the form ' $y$ exists. ${ }^{27}$ WPR only requires that, in some sense or other, what it is for the fact that a composite object exists to obtain for facts about the existence and arrangement of the xs to also obtain.

Third, note that WPR, like CAI, has no direct implications about the conditions under which composition does and does not occur. For example, the mere truth of WPR, all by itself, does not settle whether the bs compose a baseball. Indeed, WPR alone does not settle whether the bs compose anything at all. All WPR simply implies is that if the bs compose something, such as a baseball, then that baseball's existing is reduced to the bs' existing and being arranged baseball wise.

WPR does, however, entail the truth of the following principle:

\footnotetext{
${ }^{23}$ If composition is unrestricted, then the xs are "appropriately arranged" just in virtue of their existing. If composition is restricted, on the other hand, then the xs are appropriately arranged in virtue of only certain relations between the xs.

${ }^{24}$ Here is an object-reduction version of WPR: for any xs, if the xs compose an object $\mathrm{O}$, then object $\mathrm{O}$ itself is reduced to the xs themselves and how they are arranged. Equivalently, for any xs, if the xs compose object $\mathrm{O}$, then object $\mathrm{O}$ just is the xs and their arrangement. I am grateful to an anonymous referee for prompting me to think more carefully about the question of reduction's relata and that question's relevance to my arguments in this section.

25 See Rosen (2015) and Dorr (2017) on real definition.

26 See Fine (1994) on essence.

27 Thomasson (2007).
} 
Property Reduction for any xs, if the xs compose some object $\mathrm{O}$, then if $\mathrm{O}$ is $\mathrm{F}$ then the fact that $\mathrm{O}$ is $\mathrm{F}$ is reduced to some fact or facts about the properties of and interrelations among the xs. ${ }^{28}$

Property Reduction says that every fact about a given composite object is reduced to some fact or facts about that object's composing parts and interrelations among those parts. Here is a brief defense of my claim that WPR entails Property Reduction.

Suppose that Property Reduction is false. For example, suppose the fact that $\mathrm{O}$ is $\mathrm{F}$ is not reduced to any fact or combination of facts about the xs. Now, if the fact that $\mathrm{O}$ is $\mathrm{F}$ is reduced to any facts whatsoever-as opposed to being completely irreducible - presumably the fact that $\mathrm{O}$ is $\mathrm{F}$ is reduced to some fact or combination of facts about its composing parts, the xs. Therefore, the fact that $\mathrm{O}$ is $\mathrm{F}$ is a completely irreducible fact about $\mathrm{O}$.

Plausibly, for any entity $\mathrm{x}$ and property $\mathrm{F}$, if $\mathrm{x}$ is $\mathrm{F}$ and the fact that $\mathrm{x}$ is $\mathrm{F}$ is an irreducible fact about $\mathrm{x}$ then the fact that $\mathrm{x}$ exists is irreducible as well. That is, $\mathrm{x}$ 's existence is reducible only if every fact about $\mathrm{x}$ is reducible. We just saw that the fact that $\mathrm{O}$ is $\mathrm{F}$ is an irreducible fact about $\mathrm{O}$. It follows that the fact that $\mathrm{O}$ exists is also an irreducible fact. But WPR says that, for any object whatsoever, the fact that that object exists is a reducible fact. Therefore, WPR is false.

We began by supposing that Property Reduction is false. And we just concluded that WPR is false. Therefore, if Property Reduction is false then WPR is false. By contraposition, if WPR is true then Property Reduction is true. So WPR entails Property Reduction.

Suppose that, as Merricks argues, a composite object causes an effect E only if that object's microphysical parts jointly cause E. And suppose that WRP-and thus Property Reduction - is true. Then, plausibly, for any object $\mathrm{O}$ composed of some $\mathrm{xs}$, if $\mathrm{O}$ causes $\mathrm{E}$ then $\mathrm{O}$ 's causing $\mathrm{E}$ is reduced to the xs' jointly causing $\mathrm{E}$. In other words, what it is for an object to cause an effect just is for its parts to jointly cause that effect. ${ }^{29}$

Now consider the following case:

You gaze upon a grassy field. It visually appears to you as if there is a baseball, sitting in the grass. So you form the belief that there is a baseball.

\footnotetext{
28 An anonymous referee has pointed out that this principle may need to be restricted to qualitative facts, i.e. facts about the instantiation of qualitative properties by composite object $\mathrm{O}$ and facts about the instantiation of qualitative properties by O's parts, the xs. Readers who find this restricted version of the Property Reduction principle more plausible are invited to make the relevant substitutions.

29 In Merricks (2001), pp. 67-69, Merricks considers and rejects the claim that what it is for an object to cause an effect just is for its composing parts to jointly cause that effect. For, he argues, this would involve an objectionable form of circularity —one set of causal facts would be analyzed as another set of causal facts. Suppose that what it is for $\mathrm{O}$ to be $\mathrm{F}$ is for the $\mathrm{xs}$ to be $\mathrm{F}$, and that what it is for the $\mathrm{xs}$ to be $\mathrm{F}$ is for $\mathrm{O}$ to be $\mathrm{F}$. And suppose that $\mathrm{O}$ and the $\mathrm{xs}$ are non-identical. Then, perhaps, there would be objectionable circularity in the reduction of causal facts about $\mathrm{O}$ to causal facts about the xs. However, WPR does not imply that causal facts about parts are reduced to causal facts about the wholes they compose. For all WPR says, perhaps what it is for $\mathrm{O}$ to be $\mathrm{F}$ is for the $\mathrm{xs}$ to be $\mathrm{F}$, and yet it is no part of the xs being $\mathrm{F}$ that $\mathrm{O}$ is $\mathrm{F}$. Indeed, I think the fan of WPR should take Merricks' circularity concern as a reason to hold that causal facts about wholes are asymmetrically reduced to causal facts about their parts.
} 
This belief is prima facie justified for you. You also happen to accept WPRyou believe that, for any $\mathrm{xs}$, if the xs compose an $\mathrm{O}$ then what it is for $\mathrm{O}$ to exist is for there to be some xs appropriately arranged. However, you then realize that your visual experience as of a baseball is caused by a bunch of things, the bs, acting in concert.

Call this the "Baseball Reduction" case. The original Baseball case in Section I is just like the Baseball Reduction case, except that you endorse WPR in the latter case but not in the former. In the Baseball Reduction case, your belief in WPR prevents you from gaining any defeaters for your baseball belief.

First, your realization that your visual experience as of a baseball is caused by the bs does not, all by itself, serve as a defeater for your baseball belief. For your acceptance of WPR serves as a neutralizing deflector-it neutralizes the threat of defeat posed by your acceptance of that causal explanation.

Since you accept WPR, you also realize that, if there is a baseball, what it is for the baseball to cause you to believe there is a baseball is for the bs to cause you to believe there is a baseball. As a result, you can realize that, if there is a baseball, the very facts that cause you to believe there is a baseball are the very facts that constitute what it is for the baseball to cause you to have that belief. And surely that realization, all by itself, gives you no defeater for your baseball belief.

Of course, in relying on WPR in this way, you are not giving a WPR-based argument for the existence of the baseball. Given that WPR is neutral with regard to when composition occurs, such an argument would be invalid anyway. Instead, you are doing something much more modest with your belief in WPR: you are using that belief to deflect the incoming defeater for your baseball belief, which was already prima facie justified by your perceptual experience.

Second, your acceptance of WPR is a shielding deflector-it prevents you from concluding that your baseball belief is insensitive to the facts about whether there is a baseball. For an entity x's existing is reduced to some other entities, the ys, existing and being appropriately arranged only if the ys' existing and being appropriately arranged necessitates x's existence. ${ }^{30}$ This necessitation principle, like the necessitation principle governing CAI, allows you to conclude that if there had been no baseball in the field, then neither would there have been any things arranged baseball wise in the field causing you to have a baseball experience. Therefore, you can conclude, your baseball belief is not insensitive to whether or not there is a baseball in the field.

So WPR can serve as both a neutralizing deflector, neutralizing the otherwise defeating force of your realization about the causal origins of your baseball

\footnotetext{
30 Note that this necessitation principle, unlike CAI's necessitation principle, does not imply that the existence of the baseball supervenes on the mere existence of the bs alone. Instead, WPR is compatible with the more intuitive view that existence of the baseball supervenes on both the bs' existing and their being appropriately arranged. Perhaps, as some defenders of unrestricted composition think, the bs' being appropriately arranged just is the bs merely existing. Or perhaps, as many defenders of restricted composition think, there is some uniquely baseball-shaped way of arranging the bs. Thanks to an anonymous referee for helpful discussion on this point.
} 
experience, and as a shielding deflector, shielding you from concluding that your baseball belief is insensitive to whether there is a baseball.

It should now be clear that your situation in the Baseball Reduction case is more analogous to your situation in the Color Reduction case and less analogous to your situation in the Emerald City case. In the Emerald City case you do not, presumably, harbor any strange beliefs about the reducibility of facts about the tint of your glasses to facts about the city's color. In both the Color Reduction case and the Baseball Reduction case, however, you do harbor certain reduction beliefs poised to deflect the incoming defeaters.

\section{Common explanation}

Consider another case:

You receive a mysterious package in the mail. Inside, you find a pair of glasses, a large envelope, and the following note:

"Welcome to SYNC, a new experimental project in the epistemology of perception. Before proceeding any further, please put on the glasses we have provided. In the envelope, you should find a lightweight digital screen, which has one function: to display an image of a city. In order to understand the SYNC project, you need to know two things.

First, your glasses are tinted one of four possible colors: red, green, yellow, or blue. As you'll soon discover, the color of the tint changes from one day to the next. However, these changes are determined by a completely random process. Here at SYNC Headquarters, a computer algorithm randomly generates one of four primary color words every day at midnight—-'red', 'green', 'yellow', or 'blue.' Then the SYNC computer, via an instant wireless signal, will cause the tint of your glasses to change color. The computer always bases its signals on which color word was generated that day. So, for example, every day the word 'green' is generated, the computer will send a signal causing your glasses to have a green tint.

Second, the color of the digital city image changes each night at midnight as well. In fact, the same computer here at SYNC headquarters that will be causing the color of your glasses to change will also wirelessly control the color of the image each day. Crucially, the very same color word that determines which signal the computer will send to the glasses will also determine which signal is sent to the screen. So, for example, if the day's color word is 'green', the computer will send a signal to the screen that causes the image to turn green.

Since both signals are based on the same color word each day, you can always be sure that the color of the image will match the tint of your glasses." 
You believe everything the note tells you. The next day, you put the SYNC glasses on and look at the digital image on the screen. The image of the city appears green to you. You form the belief that there is a green image of a city before you. However, remembering what you read in the note, you then realize something: your experience as of a green image_-and thus your belief that there is a green image of a city before you-is fully causally explained by a color word, 'green', which was randomly generated by a computer at SYNC Headquarters.

Call this the SYNC case. It should be clear that your realization about the origins of your green city belief gives you no defeaters for that belief. For, having read the note and having believed everything it says, you also have a "common explanation" belief, which has the following content: [The city's being green and your believing it is green are both explained by the randomly generated word 'green']. That common explanation belief serves as a defeater-deflector.

First, your common explanation belief serves as a neutralizing deflector. You have realized that your green city belief is fully causally explained by the randomly generated word 'green'. Absent any other beliefs, this realization might well have been a defeater for your green city belief. However, you also believe that, if the city is green, its being green is caused by the randomly generated word 'green'. So when you realize the causal origin of your green city belief, you are merely learning that, if the city is green, then your green city belief is caused by the very same facts that cause the city to be green.

Look at it this way. If you learn that your green city belief is completely caused by some facts that do not, all by themselves, constitute good evidence for thinking the city is green then you would indeed have a defeater for your green city belief. On the other hand, if you learn that your green city belief is completely caused by some facts that are good evidence for thinking the city is green, then you gain no defeater.

But the fact that the computer generated the word 'green' is good evidence that the city is green. And so, when you realize that your green city belief is caused by the randomly generated word 'green', you have simply realized that your green city belief is caused by some facts that are good evidence for its truth. And so that realization gives you no defeater.

Second, your realizing that your green city belief is caused by the randomly generated word 'green' shields you from coming to hold that your green city belief is insensitive to the green city facts. To see this, first note if the city had not been green then the computer would not have randomly picked the word 'green.' And if the computer had not randomly picked 'green,' then the tint on your glasses would not have been green. And if the tint on your glasses had not been green, then you would not have believed that the city is green. Therefore, you can conclude, if the city had not been green then you would not have believed that it is green.

More generally, given your common explanation belief, it is hard to see how the realization that your green city belief is caused by the randomly generated word 'green' could give rise to any defeaters for your green city belief. 
Priority Pluralism (PP) is the view that, for any xs, if the xs compose an object $\mathrm{O}$, then $\mathrm{O}$ is fully grounded in the xs and their arrangement. ${ }^{31} \mathrm{PP}$-like both CAI and WPR - has no implications about which things compose a further object, nor does it have any implications about which composites there are. Specifically, PP does not imply that atoms arranged baseball wise compose something. Neither does it imply that baseball B exists.

PP does have one important implication, however. Metaphysical grounding is an explanatory relation. Thus, if $\mathrm{y}$ fully grounds $\mathrm{x}$, then $\mathrm{x}$ exists because of or in virtue of $\mathrm{y}$ 's existing. So PP implies that, if some xs compose an $\mathrm{O}$, then $\mathrm{O}$ is metaphysically explained by there being some xs appropriately arranged. ${ }^{32}$

In light of the above, consider the following case:

You gaze upon a grassy field. It visually appears to you as if there is a baseball, sitting in the grass. So you form the belief that there is a baseball. This belief is prima facie justified for you. You also happen to accept PP-you believe that, for any xs, if the xs compose an $\mathrm{O}$, then $\mathrm{O}$ is fully grounded in the xs and their being appropriately arranged. However, you realize that your visual experience as of a baseball is caused by a bunch of things, the bs, acting in concert.

Call this the "Baseball Grounding" case. The original Baseball case in Section I is just like the Baseball Grounding case, except that you endorse PP in the latter case but not in the former. I shall argue that you gain no defeaters in the Baseball Grounding case. ${ }^{33}$

First, your realization that your visual experience as of a baseball is caused by the bs does not, all by itself, serve as a defeater for your baseball belief. For your acceptance of PP serves as a neutralizing deflector-it neutralizes the threat of defeat posed by your acceptance of that causal explanation.

You have realized that your baseball belief is fully caused by the bs. Absent any other beliefs, this realization might have been a defeater for your baseball belief.

\footnotetext{
31 Defenders of priority pluralism include Cameron (2014), Skiles (2015) and Saenz (2015) among others. Priority pluralism's main rival is priority monism, defended by Jonathan Schaffer in Schaffer (2009, 2010a, b, 2012).

32 There is a dispute about whether the grounding relation is itself an explanatory relation or whether, instead, the grounding serves as a metaphysical "backing" relation for explanatory linguistic items like sentences or propositions. None of this paper's main arguments turn on which of these two views is correct-defenders of the "backing" view are thus invited to substitute, wherever appropriate, their preferred way of phrasing explanatory claims. Fine (2012), Dasgupta (2014) and Litland (2015) defend the view that grounding is itself an explanatory relation, while Audi (2012a, b) and Kim (1994) defend versions of the backing view.

33 Gideon Rosen in Rosen (2010) defends the Grounding-Reduction Link, according to which any entity $\mathrm{x}$ that is reduced to some entity $\mathrm{y}$ (or the ys) is also fully grounded in $\mathrm{y}$ (or the ys). If grounding is compatible with reduction in this way, then PP may be compatible with WPR. Call the conjunction of PP and WPR "Reductive Priority Pluralism." If you accept Reductive Priority Pluralism, then Section IV's strategy of using reduction beliefs as defeater-deflectors is available to you. However, if you, like me, think that composite objects are both fully grounded in their parts but are nevertheless irreducible to them, then you cannot make use of Section IV's reduction strategy. You can, however, make use of the common explanation strategy outlined and defended here in Section V. See Audi (2012a, b) for doubts about the compatibility of reduction and grounding.
} 
However, you also believe PP. So you can infer that the baseball, if it exists, is fully grounded in the bs and their arrangement. Since grounding is a form of metaphysical explanation, you can infer that the baseball, if it exists, exists because or in virtue of the existence and arrangement of the bs.

So your realization about the causal origin of your baseball belief amounts to a realization that, if there is a baseball, the very facts that causally explain your baseball belief are among the facts that metaphysically explain why the baseball exists. Surely that realization, all by itself, does not threaten to defeat your baseball belief.

Or look at it this way. Surely you gain no defeater by learning that your baseball belief is completely causally explained by some facts the obtaining of which are good evidence for there being a baseball, if indeed there is a baseball. But, given your belief in PP, you should think that the existence and arrangement of the bs are good evidence for the existence of the baseball, if indeed there is a baseball. So nothing you have learned gives you a defeater.

Your acceptance of PP is also a shielding deflector-it prevents you from concluding that your baseball belief is insensitive to the facts about whether there is a baseball. For the existence of a grounded entity is necessitated by its full grounds. ${ }^{34}$ Once you recognize that the existence of the baseball is necessitated in this way then, as we saw in Sect. 4 above, it would be impermissible of you to concede that your baseball belief is insensitive to the baseball facts.

Two points of clarification about your reliance upon PP as a defeater-deflector. First, as in the case of CAI and WPR, you are not giving a PP-based argument for the existence of the baseball. Given that PP is neutral about when composition occurs, such an argument would be invalid anyway. Instead, you are merely relying on PP to deflect the incoming defeater for your antecedently justified baseball belief.

Second, PP, as stated, does not entail anything about whether baseballs have any causal powers. It is consistent with PP that baseballs are such that, if they exist, they are epiphenomenal or causally inert. Nevertheless, I have just argued that you can rely on the truth of PP as a defeater-deflector. In other words, I have argued that you can preserve your baseball belief from defeat even if you do not think the baseball plays any role in the complete causal explanation of your baseball belief. ${ }^{35}$

It should also be clear that your situation in the Baseball Grounding case is more analogous to your situation in the SYNC case than it is to your situation in the Emerald City case. In the Emerald City case you do not, presumably, harbor any strange beliefs about there being some common explanation of the tint of your glasses and the facts about the city's color. In both the SYNC case and the Baseball Grounding case, however, you do harbor certain beliefs about common explanation that are in each case poised to deflect the incoming defeaters.

\footnotetext{
34 Although Skiles (2015) and Leuenberger 2014 deny that grounding is necessitating. See Trogdon (2013) for discussion.

35 Contra Korman and Locke forthcoming, who argue that conceding that the fact that p plays no explanatory role in one's $\mathrm{p}$ belief is generally a defeater for one's belief that $\mathrm{p}$. Whether such an "explanatory concession" is a defeater, so I have been arguing, depends on whether one also thinks the fact that $\mathrm{p}$, if it obtains, is fully grounded in at least some of the facts that causally explain why one believes that $\mathrm{p}$.
} 


\section{Circularity?}

The "laws of metaphysics," or "metaphysical laws" are general facts about which metaphysical relations entities of one sort bear to entities of another sort. ${ }^{36}$ As I am using the phrase "metaphysical laws," general facts about what is numerically identical with what count as laws of metaphysics. General facts about what is reduced to what, and general facts about what is metaphysically grounded in what, also count as metaphysical laws.

Metaphysical laws have the logical form of universal generalizations. ${ }^{37}$ As a result, they are existentially neutral in an important way. For example, suppose it is a law of metaphysics that every human person is identical with some human animal. All that law says is that, for any $\mathrm{x}$, if $\mathrm{x}$ is a human person then $\mathrm{x}$ is identical with some human animal. This is the sense in which this alleged law about personal identity is existentially neutral with regard to which persons exist.

Each of the above views about the relationship between composite objects and their composing parts alleges that some law of metaphysics obtains. According to CAI, it is a law of metaphysics that every composite object, if it exists, is identical with its parts. According to WPR, it is a law of metaphysics that every composite object, if it exists, is reduced to its parts. And according to PP, it is a law of metaphysics that every composite object, if it exists, is fully grounded in its parts.

I have, then, been arguing that our beliefs about the obtaining of certain metaphysical laws can serve as defeater-deflectors. Our beliefs about what metaphysical laws obtain can both neutralize the potential defeating power of a realization about the causal origins of one's belief, and they can shield us from acquiring beliefs that would, if accepted, serve as defeaters. This is the common thread running through the last three sections of this paper.

Moreover, the existential neutrality of metaphysical laws is what makes it possible to rely upon one's belief CAI, WPR, or PP as a defeater-deflector without thereby begging the question against the perceptual debunker. To see this, it may help to contrast the strategy of using our beliefs about metaphysical laws as defeater-deflectors with a case in which one's reliance upon some belief as a defeater-deflector is inarguably question-begging or otherwise illicit.

Consider the following case:

I have a strong apparent memory of seeing my coworker, Jim, emerging from a phone booth in a red cape and blue suit and then flying off into the clear blue sky. On the basis of this remarkable apparent memory, I have formed two beliefs. First, I believe that Superman exists. Second, and in part on the basis

\footnotetext{
36 See Sider (2011), Dasgupta (2016), Wasserman (2015), Wilsch 2016, Rosen (2017b), Schaffer (2017, and Glazier 2016) for more on the laws of metaphysics.

37 Those with Humean inclinations will think the laws of metaphysics are mere universal generalizations, in the same way that "all ravens are black" is a universal generalization. Non-Humeans, on the other hand, will think the "it is a law of metaphysics that" operator transforms a universal generalization into a law-like fundamental fact. I shall remain neutral between these two conceptions of the laws of metaphysics. The only thing that matters, for my purposes, is that the metaphysical laws are existentially neutral in the sense to be specified later in this section.
} 
of my belief that Superman exists, I believe that Superman is identical with Jim. However, one day a friend shows me an old recording of an office party. In the recording, Jim reveals to the office that he is also a professional hypnotist. I volunteer for an impromptu hypnotism demonstration. The recording then shows Jim hypnotizing me and, speaking very slowly, telling me that, whenever I awake, I will have a vivid memory of Jim dressed as superman and flying through the sky. After the recording ends, I refuse to give up my belief that Superman exists. "After all," I reason, "Superman is identical with Jim. Clearly, Jim caused me to believe that Superman exists. Therefore, I conclude, Superman caused me to believe that Superman exists!"38

Clearly, my reliance upon my identity belief - the belief that Superman is identical with Jim-as a defeater-deflector is objectionably circular, question-begging, or otherwise illicit.

First, notice that the proposition that Superman is identical with Jim-perhaps together with the proposition that Jim exists-just entails that Superman exists. Given that I am in a position to see that this entailment holds, when I receive a potential defeater for my belief that Superman exists, my justification for believing that Superman is identical with Jim is threatened as well.

Second, my identity belief and my belief that Superman exists have the same justificatory source. For I inferred my identity belief, in part, from my belief that Superman exists. However, my belief that Superman exists was produced and initially justified by my apparent memory. So both beliefs derive their justification, at least in part, from that memory. Therefore, when I receive a potential defeater for my belief that Superman exists, the justification for my identity belief is threatened as well.

Thus, when I realize the true origins of my apparent memory, that realization does not only threaten to undermine my justification for believing that Superman exists. In addition, that realization poses a threat to my justification for believing that Superman is identical with Jim. As a result, in relying upon my identity belief as a defeater-deflector, I am thereby relying upon one of the very beliefs whose justificatory status is threatened with defeat by the putative defeater. In this context, at least, it is impermissible of me to do so.

Is it always similarly illicit to rely upon some belief $\mathrm{b}$ as a defeater-deflector for a potential defeater $\mathrm{D}$, when $\mathrm{D}$ also threatens to undermine one's justification for believing $b$ ? This question has no uncontroversial answer. ${ }^{39}$ Fortunately, and unlike some other extant replies to the debunker, my proposed strategy for deflecting the debunker's putative defeaters does not require us to take a stand on this

\footnotetext{
38 This is a variant of a case originally formulated by Daniel Korman in his comments on an earlier draft of this paper at the Central APA 2017.

39 Andrew Moon dubs a principle completely prohibiting the use of "threatened" beliefs as defeaterdeflectors the "Anti-Circularity Principle." He offers some interesting and compelling counterexamples to that principle in Moon (2017). See Bergmann (2004) for a related discussion of "benign" versus "malignant" epistemic circularity.
} 
controversial issue in the epistemology of defeaters. ${ }^{40}$ For, in contrast with the Superman case, the content and justification of our beliefs about which metaphysical laws obtain are sufficiently independent of the content and justification of our beliefs about which objects exist.

Your belief that there is a baseball is prima facie justified by your perceptual experience as of a baseball. Furthermore, suppose you believe that CAI is true. Add that you have been convinced by the debunker that my baseball experience is fully causally explained by the joint work of some particles arranged baseball wise. This realization about the origins of your baseball experience threatens to serve as a defeater for your baseball belief. However, the justificatory status of your belief that CAI is true is not likewise threatened by your realization.

First recall that the truth of $\mathrm{CAI}$ - even together with the proposition that there are some things arranged baseball wise-does not logically entail that there is a baseball. Instead, CAI is existentially neutral with respect to when composition does or does not occur. CAI simply says that, for any xs, if they compose an object $\mathrm{O}$ then $\mathrm{O}$ is identical with the xs. So the mere logical relations between the content of the beliefs alone gives you no reason to conclude that any threat to your baseball belief doubles as a threat to your belief in CAI.

Second, your belief that CAI is true does not share a common justificatory source with your belief that there is a baseball. You did not, for example, rely upon your perceptual belief that there is a baseball in order to infer that CAI is true. Nor is your belief in CAI's truth somehow immediately produced by any sensory experience of yours.

In general, our beliefs in CAI and other laws of metaphysics are justified a priori rather than perceptually-for example, perhaps they are justified via intellectual seemings, rational intuitions, or something else. For example, many have argued for CAI, WPR, and PP on the grounds that these theories are more ontologically parsimonious than their rivals. Plausibly, neither our acceptance of certain principles of parsimony or economy nor our beliefs about which theories are parsimonious are justified on the basis of sense experience.

Perhaps the debunker would deny that a priori knowledge is possible. Or perhaps she thinks that, although a priori knowledge is possible, our beliefs about which laws of metaphysics obtain are, despite my claims to the contrary, ultimately based at least in part on the same sources of evidence that justify our existential beliefs about which composite objects exist. Or perhaps the debunker can mount an independent debunking argument targeting our otherwise a priori justified beliefs about which laws of metaphysics obtain. ${ }^{41}$

I do not know whether the debunker can eventually mount a plausible defense of one or more these claims. However, it is important to note that the burden of proof is

\footnotetext{
${ }^{40}$ As Korman and Lock forthcoming and Moon (2017) argue, the "third-factor" or "minimalist" responses to the moral debunking arguments seem to rely upon beliefs as defeater-deflectors despite those beliefs' own justification being threatened with defeat. Third-factor replies are defended by Berker (2014), Clarke-Doane (2015), and Enoch (2010).

41 For example, see Miller and Norton (2017) for a debunking argument targeting our beliefs about what grounds what.
} 
on the debunker. Until the debunker shoulders that burden, we may permissibly rely upon our beliefs about metaphysical laws as a defeater-deflector without thereby begging the question against the debunker. ${ }^{42}$

\section{Generalizing the strategy}

Let a moral belief be a belief about which moral facts obtain. For example, the belief that it is always wrong to cause unnecessary harm to one's friends and family is a moral belief. Our moral beliefs, no less than our beliefs about which composite objects exist, are the targets of debunking arguments. The moral debunking arguments usually focus on the evolutionary etiology of our moral beliefs. ${ }^{43}$

According to the debunker, we are predisposed to hold certain moral beliefs in certain contexts. When we encounter certain natural facts in our immediate environment, such as the event of one person causing another person to suffer unnecessarily, those predispositions produce occurrent moral beliefs. However, the debunker argues, we have these predispositions to form moral beliefs solely because it was conducive to the survival and reproduction of our evolutionary ancestors to hold certain moral beliefs in certain circumstances. For example, perhaps it was conducive to the survival and reproduction of our ancestors for them to believe that the causing of unnecessary harm to a friend or family member is always morally wrong.

So, according to the debunker, the complete proximate and historical causal explanation of why we have the moral beliefs we do involves only natural or nonmoral facts. The debunker concedes that we are at least prima facie justified in holding the moral beliefs we do. Nevertheless, she contends, once we realize that our moral beliefs are completely explained by the natural facts, we have thereby gained a defeater for those moral beliefs.

Suppose moral realism is true. ${ }^{44}$ There are broadly two options regarding the metaphysical relationship between the moral facts and the natural facts, given moral realism. First, perhaps the moral facts supervene upon the natural facts, but do so

\footnotetext{
42 Suppose I inferred that the baseball is identical with some atoms arranged baseballwise from my belief in CAI together with my belief that there is a baseball. Then my realization about the origins of my baseball experience would threaten my justification for believing that the baseball is identical with some particles arranged baseball-wise. At least arguably, it would therefore be illicit of me to rely on that identity belief as a defeater-deflector. However, this is not the belief I am proposing you use as a defeaterdeflector. The belief you are using as is one you can directly infer from CAI: if the particles arranged baseballwise compose a baseball then the baseball is identical with those particles.

43 See Joyce (2006) and Street (2006) for two important defenses of moral debunking arguments. And see Wielenberg (2010), Enoch (2010), Berker (2014), Clarke-Doane (2015), Moon forthcoming, Korman forthcoming, and Korman and Locke forthcoming for discussion.

44 There are two reasons I have chosen to focus on the moral realist rather than the moral antirealist. First, I suspect most moral antirealist do not believe there are any general metaphysical laws governing the relationship between moral and natural facts. Second, evolutionary debunking arguments are-at least arguably - a greater threat to the moral realist than the moral antirealist. The moral antirealist can simply concede that the moral facts play no explanatory role in the genesis of our moral beliefs. After all, part of what it is to be an antirealist is to think that our moral beliefs (and moral attitudes, more generally)
} 
"brutely" or not in virtue of any non-modal relationship between the moral and the natural. ${ }^{45}$ Second, perhaps the moral facts both supervene upon and are, in some sense or other, constituted by certain natural facts. Call this second version of moral realism "Metaethical Naturalism."

Different versions of Metaethical Naturalism postulate different general laws about how moral facts relate to their subvening natural facts. For example, Identity Naturalism says the following law of metaphysics obtains: if moral fact $\mathrm{M}$ obtains then there is some natural fact $\mathrm{N}$ (or natural facts, the $\mathrm{Ns}$ ) with which $\mathrm{M}$ is numerically identical. Similarly, let Reductive Naturalism be the view that the following law of metaphysics obtains: if moral fact $\mathrm{M}$ obtains, then there is some natural fact $\mathrm{N}$ (or natural facts, the Ns) to which $\mathrm{M}$ is reducible. Finally, let Priority Naturalism be the view that the following law of metaphysics obtains: if moral fact $\mathrm{M}$ obtains, then there is some natural fact $\mathrm{N}$ (or natural facts, the Ns) that fully grounds $\mathrm{M}^{46}$

Now suppose you are a moral realist who believes that at least one moral fact obtains. Add that you also accept either Identity Naturalism, Reductive Naturalism, or Priority Naturalism. Finally, suppose you realize that the evolutionary debunker's story is true-your moral beliefs really are fully causally explained by certain natural facts in your immediate environment together with your evolutionarilyconditioned predispositions. Have you thereby gained any defeaters for your moral beliefs?

Whether you have gained any defeaters depends on two things-which natural facts are a part of the debunker's story, and which natural facts are mentioned in the metaphysical law you believe obtains. If the very natural facts that are mentioned in the relevant metaphysical law are also an essential part of the debunker's explanation of your moral beliefs, then you have gained no defeaters for your moral beliefs.

To see this more clearly suppose, following David Enoch, that the debunker's evolutionary explanation makes essential reference to facts about what does and does not contribute to the survival and flourishing of individual human beings and of human communities. Also suppose you believe that, for any moral fact $\mathbf{M}$, if $\mathbf{M}$ obtains then $\mathrm{M}$ is either identical with, reducible to, or fully grounded in facts about the survival and flourishing of individual humans and human communities. ${ }^{47}$

In that case, when you learn that your moral beliefs are fully causally explained by facts about what is and is not conducive to the survival and flourishing of individual human beings and their communities, you have not thereby gained any

\footnotetext{
Footnote 44 continued

determine what the moral facts are, and not the other way around. Indeed, this is why moral debunking arguments are sometimes framed as arguments for antirealism. See, most notably, Street (2006).

45 G.E. Moore's view that normative properties are fundamental or sui generis properties that nevertheless modally co-vary with certain underlying natural properties is probably an instance of this version of moral realism. See Moore (1903).

46 See Rosen (2017a) for an exposition of various versions of Priority Naturalism and Berker forthcoming for criticism.

47 Enoch (2010), Section 5.3.
} 
defeaters for your moral beliefs. After all, you can reason, if there are any moral facts, the moral facts are either identical with, reduced to, or are fully grounded in facts about what is and is not conducive to the survival and flourishing of individual human beings and their communities.

In other words, your epistemic situation upon accepting the debunker's evolutionary explanation of your moral beliefs is relevantly like the epistemic situation of an advocate of CAI, WPR, or PP upon accepting that his or her object beliefs are fully causally explained by facts about those objects' putative parts. In both cases, belief in the obtaining of the relevant metaphysical law serves to deflect the force of the incoming defeater.

However, it is worth briefly noting that while the metaphysical laws deflection strategy is available to defenders of material objects of various stripes, that strategy may not be as uniformly available to every version of Metaethical Naturalism.

Most candidates for general laws about the relationship between parts and wholes include a plural quantifier ranging over all putative composers, the xs. Moreover, any plausible debunking explanation of our object beliefs will make reference to the causal activities of those same putative composers. As a result, it is almost inevitable that there should be some overlap between the content of the metaphysical laws, whatever they are, and the entities referenced in the debunking explanation. The inevitability of such overlap is what makes the proposed strategy available to defenders of CAI, WPR, and PP alike.

However, only some metaethical naturalists - those whose laws mention natural facts about the survival and flourishing of oneself, one's family, and one's immediate community_postulate metaphysical laws whose content overlaps in the right way with the natural facts postulated in the debunker's evolutionary explanation. Other moral naturalists, by contrast, may prefer metaphysical laws that do not sufficiently overlap with the facts mentioned in the debunker's explanation.

Specifically, laws that identify, reduce, or ground the moral facts exclusively in third-personal and agent-neutral natural facts may be particularly ill-suited to serve as defeater-deflectors. For example, consider a metaethical naturalism who believes we are equally obligated to give our time and resources to strangers and those who are spatially distant from us as we are to give our time and resources to friends and family. Such a metaethical naturalist may have difficulty using his or her preferred moral laws to deflect the debunker's potential defeater. Those who think morality is supremely demanding in some other way may have difficulty using the proposed strategy for similar reasons ${ }^{48}$.

This paper has proposed a strategy for resisting a perceptual debunking argument in the metaphysics of material objects, and we have just seen how the moral realist can make use of an analogous strategy to deflect the threat posed by the evolutionary debunking arguments. All of this suggests a more general upshot about when a causal explanation of one's beliefs does and does not give one a defeater for those beliefs.

\footnotetext{
48 Thanks to an anonymous referee for helpful discussion here.
} 
Suppose you believe that $\mathrm{p}$. And suppose you realize that your belief that $\mathrm{p}$ is fully causally explained by some facts, the qs. Then you have a defeater for your belief that $\mathrm{p}$ only if you do not also believe in the obtaining of some metaphysical law according to which either $\mathrm{p}$ is identical with at least one of the qs, or $\mathrm{p}$ is reduced to at least one of the qs, or $\mathrm{p}$ is fully grounded in at least one of the qs. If you have one or more of those additional beliefs, then you gain no defeater.

The upshot is that the debunker has two options. She can either be content with debunking only the beliefs of those who do not accept that the relevant laws of metaphysics obtain, or she can widen her target audience and shoulder a much bigger burden of proof. If the debunker plans to widen her audience, she must also be ready to debunk beliefs about what is identical with what, what is reduced to what, and what grounds what.

Acknowledgements I am grateful to Robert Audi, Jeff Brower, Ross Cameron, James Darcy, Dustin Crummett, Torrance Fung, Kirra Hyde, David Mark Kovaks, Derek Lam, Kris McDaniel, Andrew Moon, Sam Murray, Sam Newlands, Fr. Phillip Neri-Reese, Mike Rea, Nick Rimell, Aurora Raske, Noel Saenz, Jeff Snapper, Rebecca Stangl, Adam Tiller, two anonymous referees for this journal, and audiences at the 2016 Virginia Philosophical Association meeting, the APA Central 2017, and Notre Dame's Center for Philosophy of Religion paper workshop for helpful discussion. I am especially grateful to Dan Korman, Trenton Merricks, and Peter Tan, all of whom multiple drafts of this paper and provided me with invaluable feedback, advice, and discussion. Dan gave excellent comments on an earlier draft of the paper at the APA and gave me lots of helpful advice before and after our session. The paper's current framing, and most of the material in Section VI, are a direct result of his comments and advice.

\section{References}

Audi, P. (2012a). Grounding: Toward a theory of the in-virtue-of relation. Journal of Philosophy, $109(12), 685-711$.

Audi, P. (2012b). Audi, Paul. A clarification and defense of the notion of grounding. In C. Fabrice \& S. Benjamin (Eds.), Metaphysical grounding: Understanding the structure of reality (pp. 101-121). New York, NY: Cambridge University Press.

Baxter, D. (1988). Many-one identity. Philosophical Papers, 17(3), 193-216.

Bergmann, M. (2004). Epistemic circularity: Malignant and benign. Philosophy and Phenomenological Research, 69(3), 709-727.

Berker, S. (2014). Does evolutionary psychology show that normativity is mind dependent. In J. D'Arms \& D. Jacobson (Eds.), Moral psychology and human agency (pp. 215-252). Oxford: Oxford University Press.

Berker, S. (forthcoming). The explanatory ambitions of moral principles. Noûs.

Cameron, R. (2012). Composition as identity doesn't settle the special composition question. Philosophy and Phenomenological Research, 84(3), 531-554.

Cameron, R. (2014). Parts generate the whole, but they are not identical to it. In D. Baxter \& A. Cotnoir (Eds.), Composition as identity (pp. 90-107). Oxford: Oxford University Press.

Clarke-Doane, J. (2015). Justification and explanation in mathematics and morality. Oxford Studies in Metaethics, 10, 80-103.

Dasgupta, S. (2014). The Possibility of physicalism. Journal of Philosophy, 111(9-10), 557-592.

Dasgupta, S. (2016). Metaphysical rationalism. Nô̂s, 50(2), 379-418.

Dorr, C. (2017). To be F is to be G. Philosophical Perspectives, 30(1), 39-134.

Enoch, D. (2010). The epistemological challenge to metanormative realism: how best to understand it, and how to cope with it. Philosophical Studies, 148(3), 413-438.

Fine, K. (1994). Essence and modality. Philosophical Perspectives, 8, 1-16.

Fine, K. (2012). Guide to ground. In F. Correia \& B. Schnieder (Eds.), Metaphysical grounding (pp. 37-80). Cambridge: Cambridge University Press. 
Glazier, M. (2016). Laws and the completeness of the fundamental. In M. Jago (Ed.), Reality making. Oxford: Oxford University Press.

Joyce, R. (2006). The evolution of morality. Cambridge: MIT Press.

Kim, J. (1994). Explanatory knowledge and metaphysical dependence. Philosophical Issues, 5, 51-69.

Korman, D. Z. (2015). Objects: Nothing Out of the Ordinary. Oxford: Oxford University Press.

Korman, D. Z. (forthcoming). Debunking arguments in metaethics and metaphysics. In A. Goldman \& B. McLaughlin (eds.), Metaphysics and cognitive science.

Korman, D. Z., \& Locke, D. (forthcoming). Against Minimalist Responses to Moral Debunking Arguments. Oxford Studies in Metaethics.

Leuenberger, S. (2014). Grounding and Necessity. Inquiry, 57, 151-174.

Lewis, D. (1991). Parts of classes. Oxford: Blackwell.

Litland, J. E. (2015). Grounding, explanation, and the limit of internality. Philosophical Review, 124(4), 481-532.

Markosian, N. (1998). Simples. Australasian Journal of Philosophy, 76, 213-226.

McDaniel, K. (2009). Extended simples and qualitative heterogeneity. The Philosophical Quarterly, 59, 325-331.

Merricks, T. (1999). Composition as identity, mereological essentialism, and counterpart theory. Australasian Journal of Philosophy, 77(2), 192-195.

Merricks, T. (2001). Objects and persons. New York, NY: Oxford University Press.

Merricks, T. (2003). Replies to Lowe, Dorr, and Sider. Philosophy and Phenomenological Research, 67, 727-744.

Merricks, T. (2005). Composition and vagueness. Mind, 114(455), 615-637.

Merricks, T. (2016). Do ordinary objects exist? No. In E. Barnes (Ed.), Current controversies in metaphysics. New York, NY: Routledge Press.

Miller, K., \& Norton, J. (2017). Grounding: it's all in the head. Philosophical Studies, 174(12), 3059-3081.

Moon, A. (2017). Debunking morality: Lessons from the EAAN literature. Pacific Philosophical Quarterly, 98(S1), 208-226.

Moore, G. E. (1903). Principia ethica. Mineola, NY: Dover Publications.

Parsons, J. (2004). Distributional properties. In F. Jackson \& G. Priest (Eds.), Lewisian Themes: The philosophy of David K Lewis (pp. 173-180). Oxford: Oxford University Press.

Plantinga, A. (1993). Warrant and proper function. New York, NY: Oxford University Press.

Plantinga, A. (2011). Where the conflict really lies: science, religion, \& naturalism. Oxford: Oxford University Press.

Rosen, G. (2010). Metaphysical dependence: Grounding and reduction. In B. Hale \& A. Hoffmann (Eds.), Modality: Metaphysics, logic, and epistemology (pp. 109-136). Oxford: Oxford University Press.

Rosen, G. (2015). Real definition. Analytic Philosophy, 56(3), 189-209.

Rosen, G. (2017a). Metaphysical relations in metaethics. In T. McPherson \& D. Plunkett (Eds.), The Routledge handbook of metaethics. Routledge, pp. 151-169.

Rosen, G. (2017b). Ground by law. Philosophical Issues, 27(1), 279-301.

Saenz, N. B. (2015). A grounding solution to the grounding problem. Philosophical Studies, 172(8), 2193-2214.

Schaffer, J. (2009). On what grounds what. In D. Manley, D. J. Chalmers, \& R. Wasserman (Eds.), Metametaphysics: New essays on the foundations of ontology (pp. 347-383). Oxford: Oxford University Press.

Schaffer, J. (2010a). Monism: The priority of the whole. Philosophical Review, 119(1), 31-76.

Schaffer, J. (2010b). The internal relatedness of all things. Mind, 119(474), 341-376.

Schaffer, J. (2012). Why the world has parts: Reply to Horgan and Potrc. In Goff (Ed.), Spinoza on Monism.

Schaffer, J. (2017). Laws for metaphysical explanation. Philosophical Issues, 27(1), 302-321.

Sider, T. (2003). What's so bad about over determination? Philosophy and Phenomenological Research, 67(3), 719-726.

Sider, T. (2007). Parthood. Philosophical Review, 116(1), 51-91.

Sider, T. (2011). Writing the book of the world. Oxford: Oxford University Press.

Skiles, A. (2015). Against grounding necessitarianism. Erkenntnis, 80(4), 717-751.

Street, S. (2006). A Darwinian dilemma for realist theories of value. Philosophical Studies, 127, 109-166.

Tan, P. (forthcoming). Counterpossible non-vacuity in scientific practice. Journal of Philosophy.

Thomasson, A. L. (2007). Ordinary objects. Oxford: Oxford University Press. 
Trogdon, K. (2013). Grounding: Necessary or contingent? Pacific Philosophical Quarterly, 94(4), $465-485$.

Wasserman, R. (2017). Vagueness and the laws of metaphysics. Philosophy and Phenomenological Research, 95(1), 66-89.

Wielenberg, E. J. (2010). On the evolutionary debunking of morality. Ethics, 120, 441-464.

Wilsch, T. (2016). The deductive-nomological account of metaphysical explanation. Australasian Journal of Philosophy, 94(1), 1-23.

Publisher's Note Springer Nature remains neutral with regard to jurisdictional claims in published maps and institutional affiliations. 